\title{
ASPECTOS PENALES DE LA REFORMA TRIBUTARIA
}

\author{
CRIMINAL ASPECTS OF THE TAX REFORM
}

ASPECTS PÉNALS DE LA RÉFORME DES IMPÔTS

Jean Pierre Matus Acuña*

El Proyecto de Ley de Reforma Tributaria aprobado por el Congreso y a punto de ser promulgado por la Presidenta de la República, tras su revisión por el Tribunal Constitucional, contempla diversas "nuevas" infracciones que podrían sancionarse penalmente.

Algunas de ellas, sin embargo, son sólo reformulaciones específicas de normas generales que se estimaron necesarias dada la nueva estructura del sistema impositivo y sus hechos gravados. Así, en relación con las nuevas regulaciones aplicables a inversiones en el extranjero y en Chile, se incorporan una serie de obligaciones de información cuya omisión o falseamiento doloso se castiga conforme a la regla general del artículo 97 No 4 del Código Tributario, inciso $1^{\circ}$, a saber:

i) La entrega maliciosa de información incompleta o falsa en las declaraciones sobre inversiones en el extranjero que deban hacerse tanto por quienes se encuentran afectos al régimen tributario de renta efectiva o atribuida (artículo 14, letra E, 1, a) de la Ley de Impuesto a la Renta, con vigencia a partir del año 2017);

ii) La entrega maliciosa de información incompleta o falsa en las declaraciones sobre la calidad de constituyente, settlor, beneficiario, trustee o administrador de un trust creado conforme a disposiciones de derecho extranjero por contribuyentes o entidades domiciliadas, residentes, establecidas o constituidas en el país, sean o no sujetos del impuesto a la renta (artículo 14, letra E, 1, a) de la Ley de Impuesto a la Renta, con vigencia a partir del año 2017);

iii) La entrega maliciosa de información incompleta o falsa en la declaración jurada sobre deudas, garantías y beneficiarios de los intereses, comisiones, remuneraciones por servicios y gastos financieros y cualquier otro recargo convencional, incluyendo los que correspondan a reembolsos, recargos de gastos incurridos por el acreedor o entidad relacionada en beneficio directo o indirecto de otras empresas relacionadas en el exterior que afecten los resultados del contribuyente domici-

* Abogado. Licenciado en Derecho por la Pontificia Universidad Católica de Chile. Magíster y Doctor en Derecho por la Universidad Autónoma de Madrid, España. Profesor Titular de Derecho Penal e Investigador de la Facultad de Derecho, Universidad de Chile, Santiago, Chile. Correo electrónico: jpm@matusyramirez.cl. 
liado, residente, establecido o constituido en el país, en virtud de los préstamos, instrumentos de deuda y otros contratos u operaciones, y que correspondan al exceso de endeudamiento determinado al cierre del ejercicio, que implique la no aplicación de lo dispuesto en los números 1 a 11 del artículo $41 \mathrm{~F}$ de la Ley de Impuesto a la Renta para la determinación del impuesto único que allí se establece sobre dichos intereses y demás conceptos referidos (artículo 14, letra E, 1, a) de la Ley de Impuesto a la Renta, con vigencia a partir del año 2017);

iv) La declaración maliciosamente falsa de las informaciones que el Servicio de Impuestos Internos determine para los efectos de aplicar y fiscalizar el cumplimiento de lo dispuesto en el artículo $41 \mathrm{G}$ de la Ley de Impuesto a la Renta, a efectos de determinar las rentas pasivas que deban considerarse percibidas o devengadas en Chile por contribuyentes o patrimonios de afectación con domicilio, residencia o constituidos en Chile, que directa o indirectamente controlen entidades sin domicilio ni residencia en el país (artículo 41 G, G) de la Ley de Impuesto a la Renta, con vigencia a partir del año 2016);

Con todo, no se debe olvidar que al establecerse una disposición especial, el intérprete se haya obligado a escudriñar en el texto de la ley el sentido de tal especialidad. De la literalidad de los textos reseñados, comparados con lo dispuesto en el artículo 97 No 4 del Código Tributario, es claro que estas nuevas figuras mantienen la referencia al carácter malicioso de la conducta para su punibilidad añadiendo que ella se extiende a obligaciones antes inexistentes y por ello ahora especiales y, al mismo tiempo, hacen omisión del requisito objetivo con que se completa la descripción de la figura genérica del artículo 97 No 4, esto es, su potencialidad para inducir a la liquidación de un impuesto inferior al que corresponda, requisito ya no exigible a estas nuevas figuras.

Otras normas penales del Proyecto, que parecen "nuevas" son, sin embargo, más bien un renacimiento de viejas infracciones relacionadas con los mecanismos de control de los impuestos específicos, cuyas cuantías y casos se amplían. Así, ahora se ordena nuevamente sancionar como venta clandestina o contrabando, según los casos,la extracción o el retiro de productos o artículos gravados con impuestos específicos de las fábricas, bodegas, almacenes o depósitos de productos en que se encontrasen sin la faja fiscal que acredite el pago del impuesto respectivo y permita su trazabilidad, salvo que se acredite haber pagado el impuesto que se trate (inciso $6^{\circ}$ artículo 13 bis D.L. No 828/1974, con vigencia al mes de publicada la ley, para el caso de los tabacos; e inciso $6^{\circ}$ artículo 60 quinquies del Código Tributario, con vigencia al año de publicada la ley, aplicable a todo producto con impuesto específico). El mismo efecto déjà vu produce la lectura del "nuevo" delito de adulteración maliciosa en cualquier forma de los productos o inventarios objeto de impuestos específicos, o de la información que respecto de aquellos se proporcione al Servicio de Impuestos Internos, con la finalidad de determinar un impuesto inferior al que corresponda, contemplado en los que serán nuevos inciso $8^{\circ}$ artículo 13 bis D.L. No 828/1974, e inciso $8^{\circ}$ del artículo 60 del Código Tributario, con vigencia a partir 
del mes y año siguiente a la publicación de la ley, respectivamente. Como correlato de esta especial atención a los bienes gravados con impuestos específicos, el Proyecto de Reforma Tributaria reformula el artículo 178 de la Ordenanza de Aduanas para señalar que al autor de contrabando de "mercancía afecta a tributación especial o adicional" se le impondrá la pena privativa de libertad, aumentada en un grado.

Las "nuevas" formas de contrabando relacionadas con la expedición al extranjero de mercancías fuera de los pasos habilitados o sin haber sido debidamente declaradas, recuerdan los tiempos en que los ingresos de la Patria dependían exclusivamente de los impuestos de importación y exportación (y sobre todo de estos últimos). Y aunque no se han establecido impuestos generales de exportación, sí existen productos cuya extracción y exportación es gravada con royalties y, sobre todo, de manera indirecta, al constituir los ingresos por exportación parte importante de la base de cálculo de los impuestos a la renta, parece justificado el interés fiscal por la corrección de las operaciones y las declaraciones que de ellas se hagan. Por ello es razonable haber incorporado, con vigencia a partir de enero de 2015, un nuevo inciso en el artículo 168 de la Ordenanza de Aduanas que declare incurrir "también" en el delito de contrabando al que extraiga mercancías del país por lugares no habilitados o sin presentarlas a la Aduana; y otro al artículo 169 de dicho cuerpo legal que sanciona penalmente a aquellos consignantes de mercancías que salen del país, que presenten documentos falsos, adulterados o parcializados, para servir de base a la confección de las declaraciones, determinándose a través de ellos la clasificación o valor de las mercancías.

Hay también en el Proyecto aprobado disposiciones penales con vigencia tan limitada en el tiempo que, con razón, se encuentran en su disposición transitoria vigésimo cuarta, pues dicen relación con el régimen especial de repatriación de fondos en el extranjero que operará sólo el año 2015, sancionándose penalmente a los contribuyentes que, maliciosamente y con infracción a la regulación especial establecida al efecto, incluyan en su propia declaración bienes o rentas de terceros; y al funcionario público que viole el secreto con que se reviste esta extraordinaria forma de regularizar fondos e impuestos en el país. Su aplicación podría suscitar, en el futuro, alguna discusión precisamente en torno a su vigencia temporal, pero es posible adelantar que por corto que sea el tiempo en que los hechos punibles se puedan cometer, lo cierto es que la ley misma, a pesar de su carácter transitorio, mientras no se derogue por un acto legislativo posterior, seguirá vigente y susceptible de aplicación mientras los hechos punibles no prescriban.

Hasta aquí, las disposiciones penales incorporadas en el Proyecto de Ley de Reforma Tributaria responden al principio general de que en un sistema tributario basado en las declaraciones de los contribuyentes sin fiscalización previa son tales declaraciones las que determinan prima facie los ingresos totales, la base imponible y los impuestos y tasas aplicables. Esto es, que la integridad del sistema tributario y la recaudación de los fondos necesarios para la realización de las labores de gobierno dependen, a su vez, de la integridad de las declaraciones de los contribuyentes. 
En todos los sistemas así construidos una declaración que oculta los ingresos del contribuyente, omite deliberada, intencional o maliciosamente hechos gravados o distorsiona del mismo modo sus libros y documentos contables para disminuir la base imponible es considerada generalmente como un delito de evasión de impuestos.

Esto es lo que, precisamente, tratan de reforzar las nuevas normas que se introducen respecto de las inversiones en Chile y el exterior, así como en relación a las denominadas rentas pasivas y a la nueva obligación de retención respecto de las deudas y otras operaciones con empresas relacionadas del exterior.

A lo mismo apunta el castigo penal de la simple y llana burla de los sistemas de control, esto es, la no presentación de las declaraciones que sirven de base para la determinación del impuesto, que se castiga con las nuevas formas de contrabando y omisión de declaración agregadas a la Ordenanza de Aduanas. El castigo de la venta clandestina de mercancías sin pagar el impuesto específico correspondiente también apunta hacia esa gama de comportamientos de simple y llana burla del sistema de control tributario. El Código Tributario contemplaba formas generales de esta clase de hechos (el artículo $97 \mathrm{No}^{\circ}$ s. 5, 8 y 9), pero sólo la venta clandestina tiene una regla más bien formal, semejante a la del nuevo artículo 60 quinquies, que la especifica respecto de los objetos sujetos a controles como la faja fiscal; mientras la no presentación de declaraciones, equivalente a las nuevas formas de contrabando, se castiga penalmente sólo cuando es hecha de forma maliciosa.

Fuera de estos casos y otros semejantes, en los sistemas de declaración voluntaria, la manifestación completa de los ingresos y gastos que representen operaciones reales, acompañada o no del pago de los impuestos que el contribuyente estima corresponder no constituye en principio delito, y si los impuestos declarados no se pagan o el cálculo que de los mismos hace el contribuyente no corresponde a los que debiera pagar, el asunto tendría un carácter civil o administrativo solamente. En efecto, aquí de lo que se trataría únicamente sería de la determinación del monto a pagar o de su cobranza, labores para las cuales precisamente se establecen los Servicios de Impuestos en todo el mundo. Luego, el error del contribuyente en sus imputaciones tributarias o una diferente apreciación del mismo frente a la del Servicio acerca del impuesto o tasa a pagar no constituye delito y probablemente tampoco infracción administrativa, si se han declarado las operaciones realmente efectuadas y todos los antecedentes que permiten la determinación de la base imponible y del impuesto a pagar en definitiva.

Entre un extremo y el otro la Reforma Tributaria introduce ahora entre nosotros la elusión tributaria, como un hecho ilícito administrativamente, pero no en todos los casos punible. De conformidad con el texto de la Reforma Tributaria, podríamos definir la elusión tributaria como "el conjunto de arreglos y operaciones formalmente lícitas que el contribuyente declara oportunamente, pero que realiza sin otro efecto económico o jurídico que el de no pagar impuestos, diferir indefinidamente su pago, crear exenciones o imputaciones artificiales, o pagar una suma menor a la que correspondería de no mediar tales operaciones". 
Para hacer frente a tales arreglos y operaciones la Reforma Tributaria declara explícitamente que la licitud formal de las operaciones declaradas sólo se presume, pero que los impuestos se han de determinar conforme a la naturaleza sustancial o material de las mismas. Es decir, la ley sólo presume legalmente la buena fe del contribuyente, sometiendo a una regla probatoria no sólo la comprobación de la inexistencia de dicha buena fe sino también el efecto tributario de la misma. Esta"buena fe" se pierde cuando, si el Servicio determina una diferencia de impuestos de más de 250 unidades tributarias anuales, recurre ante el Tribunal Tributario y Aduanero correspondiente para que éste declare la existencia de la elusión en sus formas de abuso de las formas jurídicas o simulación por parte del contribuyente. Según los nuevos artículos 4 ter y 4 quáter del Código Tributario, hay abuso de las formas jurídicas cuando con su empleo"se evite total o parcialmente la realización del hecho gravado, o se disminuya la base imponible o la obligación tributaria, o se postergue o difiera el nacimiento de dicha obligación, mediante actos o negocios jurídicos que, individualmente considerados o en su conjunto, no produzcan resultados o efectos jurídicos o económicos relevantes para el contribuyente o un tercero, que sean distintos de los meramente tributarios"; y hay simulación, "cuando los actos y negocios jurídicos de que se trate disimulen la configuración del hecho gravado del impuesto o la naturaleza de los elementos constitutivos de la obligación tributaria, o su verdadero monto o data de nacimiento". La cláusula general antielusiva del nuevo artículo $4^{\circ}$ bis establece que, en tales casos, previa declaración de abuso o simulación, el Servicio está habilitado para determinar y girar los impuestos aplicables de conformidad con la real naturaleza de las operaciones realizadas, pudiendo no tomar en cuenta aquellas que fueren abusivas o conferirles su sentido sustancial a aquellas simuladas. En tales casos se establece, además, una responsabilidad administrativa especial de los consejeros tributarios que hubieren diseñado o planificado tales operaciones abusivas o simuladas consistente en una multa de hasta un $100 \%$ de todos los impuestos que debieren haberse pagado con un tope de 100 UF (artículo 100 bis del Código Tributario, en vigencia al año de publicada la ley).

Pero dicha cláusula general del nuevo artículo $4^{\circ}$ bis del Código Tributario se cuida también de dejar a salvo la regulación ya existente y las llamadas cláusulas especiales antielusión, al disponer que "en los casos en que sea aplicable una norma especial para evitar la elusión, las consecuencias jurídicas se regirán por dicha disposición" y no por las especiales que se establecen al regular el abuso y la simulación.

$\mathrm{Y}$ es por ello que los casos especiales de abuso y simulación constitutivos de delito no requerirán del nuevo procedimiento de declaración de los mismos del flamante artículo 160 bis que esta Reforma agrega al Código Tributario y que exige, como condición para que el Director la solicite, una diferencia de impuestos liquidados de más de 250 unidades tributarias mensuales (artículo $4^{\circ}$ quinquies de la Ley de Impuesto a la Renta). Y tampoco en tales casos la responsabilidad de quienes hubieren diseñado o planificado tales operaciones se encontraría sujeta a la declaración 
del Tribunal Tributario y Aduanero correspondiente, sino a las reglas generales de los artículos 14, 15 y 16 del Código Penal y 100 del Código Tributario.

Uno de estos casos especiales de simulación es de antigua data y se encuentra en el vigente inciso $3^{\circ}$ del artículo 97 No 4 del Código Tributario, donde se castiga con las penas que allí se indican, si así lo decide denunciar el Director del Servicio, al que obtuviere devoluciones de impuestos que no le correspondan, simulando una operación tributaria inexistente. Es claro que, aunque imaginable de forma aislada, en realidad el legislador ha castigado acá una forma extrema de lo que se sanciona en el inciso $2^{\circ}$ de dicha disposición, esto es, el aumento mediante cualquier maniobra del verdadero monto de los créditos e imputaciones que deban hacerse, en relación con las cantidades a pagar, respecto de los impuestos de retención o recargo. En este inciso, aunque la ley no lo exprese directamente, la simulación también ha de considerarse una de tales "cualquiera maniobras", pues, por una parte, no existe una limitación literal a esta interpretación y, por otra, resultaría incomprensible no entenderlo así, dado que la simulación permite tanto aumentar las imputaciones contra lo que se debe pagar como sobrepasarlas, al punto de solicitar una devolución indebida de las mismas.

En el Proyecto de Ley de Reforma Tributaria se establece, además, un delito especial de abuso de formas jurídicas, consistente en la utilización abusiva, hecha maliciosamente, de empresas, entidades o sociedades domiciliadas, residentes, establecidas o constituidas en Chile que obtengan rentas pasivas de acuerdo a los criterios que establece el artículo $41 \mathrm{G}$, realizada con la finalidad de evitar, disminuir o postergar la aplicación de los impuestos global complementario o adicional de sus propietarios, socios o accionistas (artículo 14, letra E, 1, b) de la Ley de Impuesto a la Renta, con vigencia a partir del año 2017).

Si hemos de seguir el predicamento señalado para los casos especiales de simulación constitutiva de delito, este caso especial de abuso constitutivo de delito debiera seguir los mismos principios: no estaría sujeto a declaración de abuso por parte del Tribunal Tributario y Aduanero y, por tanto, tampoco a la limitación de la cuantía de la diferencia de impuestos. Su ubicación al final del apartado respectivo, donde al principio del mismo y para el caso de abuso no malicioso se reconoce la necesidad de tal declaración, y su frase inicial: "no obstante lo anterior”, parecen confirmar lo que aquí se sostiene. Aquí, a los elementos objetivos del abuso se añaden indicaciones subjetivas acerca del carácter malicioso del mismo y su finalidad especifica de evitar, disminuir o postergar los impuestos global complementario o adicional.

Desde el punto de vista que aquí se ha adoptado, todavía podría plantearse la cuestión acerca de si ciertas formas de abuso y simulación pudiesen considerarse también como procedimientos dolosos encaminados a ocultar o desfigurar el verdadero monto de las operaciones realizadas o a burlar el impuesto (artículo 97 No 4, inciso $\left.1^{\circ}\right)$. Desde luego, a ello no se opone la literalidad del texto legal. Mucho menos el hecho de que tales conductas ya no serán lícitas por regla general -al menos no 
cuando se trata de determinar los impuestos a la renta-, aunque se presuma de manera simplemente legal la buena fe del contribuyente.

La cuestión verdaderamente relevante sería entonces determinar qué diferenciaría el abuso y la simulación sancionables administrativamente de aquellos constitutivos de delito.

Los textos de los tres casos mencionados apuntan en una dirección que podríamos llamar subjetiva: el carácter malicioso o doloso del abuso o simulación, ya que es presupuesto en todos los casos que su resultado, desde el punto de vista objetivo, sea la reducción, postergación o evitación del pago del impuesto correspondiente, y en los casos de impuestos de retención o recargo, la obtención, además, de devoluciones improcedentes.

Esta misma diferenciación aparece ya en el Código Tributario, particularmente en el caso de la distinción entre omisión de una declaración que sirva de base para la determinación del impuesto que constituye mera infracción tributaria (artículo 97 No 2) y el delito consistente en la omisión maliciosa de declaraciones exigidas por las leyes tributarias para la determinación o liquidación de un impuesto (artículo 97 No 5).

$\mathrm{Al}$ respecto, la doctrina y jurisprudencia mayoritarias se han pronunciado afirmando que la malicia en el contexto de los delitos tributarios significaría dolo directo, con exclusión del dolo eventual. Felipe Amunátegui había sostenido, en cambio, que se trataba de una regla que exigiría la prueba del dolo, desvirtuando la presunción del artículo $1^{\circ}$ del Código Penal. Últimamente, Alex van Weezel, rechaza ambas interpretaciones, siguiendo la minoritaria doctrina de Jakobs que tiende a expulsar del contenido de la ilicitud y de la culpabilidad toda manifestación de la subjetividad humana (o más bien tendía, ya que ahora último le reconoce alguna influencia), transformado el dolo (y en este caso, la malicia) en una cuestión de imputación objetiva o atribución social de sentido, como si se dijese que con ello se quiere significar una mayor gravedad del hecho o una interpretación social del mismo que ex re lo considere más grave (=malicioso), sin atención a la subjetividad del agente.

A mi juicio, la tesis de Amunátegui no es incompatible con la de la doctrina mayoritaria, pues nada impide afirmar que el dolo directo exigible en estos delitos deba probarse sin recurrir a la presunción del artículo $1^{\circ}$ del Código Penal. Es más, ésta sería la única forma real de distinguir los casos del artículo 97 No 2 de los del artículo 97 No 5 (y, por ende, los casos donde el abuso y la simulación no son delito de aquellos que sí), pues una deducción del dolo directo ex re, esto es, exclusivamente a partir de la objetividad del hecho no ofrecería en la realidad distinción alguna, sino quedaría entregada a la apreciación subjetiva del Director del Servicio, en primer lugar, y del Tribunal, en segundo término, sin posibilidad de ofrecer prueba contraria o desvirtuar la que se presente. Ese es también el problema de fondo de la propuesta de van Weezel, como de toda la propuesta de Jakobs: al radicar la apreciación de los elementos del delito en la mente del juez (al final, 
quien determina el "sentido social" de los hechos) sin un correlato probatorio intersubjetivamente comprobable e inteligible se suprimen exigencias probatorias sin que la ley así lo exija, por la simple vía interpretativa. Al mismo tiempo, la simplificación y a la postre supresión de la prueba del dolo, reemplazándola por la simple atribución judicial no parece distinguirse en la práctica de los supuestos de responsabilidad objetiva a que, tendencialmente, conduce la doctrina que identifica la ilicitud penal no con el cumplimiento concreto de los presupuestos legales de un hecho punible determinado sino con la idea abstracta y objetiva del incumplimiento de deberes (extrapenales).

En conclusión, dado que la responsabilidad meramente infraccional o administrativa puede objetivizarse y no requiere en todo caso la prueba de la subjetividad humana, como acontece con la que se hace exigible a los contribuyentes que son personas jurídicas o entidades asimiladas (comunidades de hecho, etc.), el abuso y la simulación comprobados objetivamente han de sancionarse de conformidad con las reglas generales antielusivas, mediante el procedimiento especial de declaración del nuevo artículo 160 bis del Código Tributario. Cuando tal abuso y simulación constituyan a la vez infracciones del artículo 97 del Código Tributario, especialmente de su No 4, es discutible que no sea también exigible tal declaración, ya que el Director del Servicio no parece estar ahora facultado para hacerla por sí mismo. Pero lo que no es discutible es que cuando el abuso o la simulación constituyan elementos de un delito tributario, no será el Director del Servicio, sino el Tribunal en lo criminal quien establezca su existencia como elemento del delito que se trate, de conformidad con las pruebas recibidas y, además, sólo podrá condenarse por el delito que se trate, siempre que, adicionalmente, la malicia o dolo directo en la evasión de impuestos o en la obtención indebida de devoluciones se pruebe con evidencias diferentes de aquellas empleadas para acreditar dicho abuso o simulación. 